\title{
A Brief Review of Integrated Counseling and Testing Center in RajaRajeswari Medical College and Hospital, Bengaluru, Karnataka, India
}

\author{
${ }^{1}$ Shashikala Manjunatha, ${ }^{2}$ Subramanian Aishwarya, ${ }^{3}$ Rangenahalli V Anuradha
}

\begin{abstract}
Introduction: The National AIDS (acquired immunodeficiency syndrome) Control Programme Phase four has envisaged the strengthening activities for prevention and control of AIDS through Integrated Counseling and Testing Center (ICTC)-a unit, where a person is counseled and tested for human immunodeficiency virus (HIV) through direct access or by physician referral. For HIVIAIDS victims, ICTCs are nodal points for preventive, curative, and supportive services.
\end{abstract}

Objective: To assess the patient's profile in an ICTC of a private medical college hospital in Bengaluru, India, during the years 2014 to 2017.

Materials and methods: The study was conducted by record review and interviewing of patients attending ICTC of a private medical college hospital in Bengaluru. Statistical tests applied included univariate analysis and Chi-square test.

Results: This study depicted the functions and utilization pattern of services from a hospital-based ICTC attached to a medical college, through public-private partnership. The brief details of clients attending ICTC are reflected here. Among the total patients of 46,152 for 3 years referred to ICTC, 265 were HIV positive.

Conclusion: Here HIV positive cases are more among agriculturists and lower socioeconomic status persons, and sexual mode is the predominant mode of transmission.

Keywords: Human immunodeficiency virus positives, Integrated Counseling and Testing Center, Lower socioeconomic status.

How to cite this article: Manjunatha $S$, Aishwarya $S$, Anuradha RV. A Brief Review of Integrated Counseling and Testing Center in RajaRajeswari Medical College and Hospital, Bengaluru, Karnataka, India. J Med Sci 2018;4(2):60-62.

Source of support: Nil

Conflict of interest: None

\section{INTRODUCTION}

A global estimate revealed that the number of persons with HIV in 2016 was 36.7 million (30.8-42.9 million). ${ }^{1}$

\footnotetext{
${ }^{1}$ Professor and Head, ${ }^{2,3}$ Postgraduate Student

${ }^{1-3}$ Department of Community Medicine, RajaRajeswari Medical College \& Hospital, Bengaluru, Karnataka, India

Corresponding Author: Shashikala Manjunatha, Professor and Head, Department of Community Medicine, RajaRajeswari Medical College \& Hospital, Bengaluru, Karnataka, India, e-mail: shashi_aishu@yahoo.com
}

Adults aged between 15 and 49 years contributed to $0.8 \%$ of the burden of HIV1 disease. A national estimate revealed 80,000 (62,000-100,000) new HIV infections and 62,000 $(43,000-91,000)$ AIDS-related deaths in 2016. There were 2,100,000 $(1,700,000-2,600,000)$ people living with HIV, among whom $49 \%$ (40-61\%) were accessing antiretroviral therapy in $2016 .^{2}$

Prevalence of HIV among the adult population in India has substantially declined from 0.4 to $0.26 \%$ over the last two decades, with a reduction of $66 \%$ in new HIV infection among adults. ${ }^{3}$ This clearly reflects works of National AIDS Control Organization.

India is a signatory with full commitment toward the global vision to end HIV/AIDS as a public health threat by $2030 .{ }^{4}$ Scaling up of HIV counseling and testing services, with ensuring privacy and confidentiality, has been an integral component of National AIDS Control Programme. ${ }^{5}$

An ICTC is a place where a person is counseled and tested for HIV. The client utilizes the ICTC services by his own free will or as advised by medical provider. The client is assured that the process will be confidential. ${ }^{6}$ Integrated Counseling and Testing Center has the following benefits:

- It increases awareness about HIV/AIDS and its modes of transmission.

- It strengthens prevention and facilitates behavior change (risk reduction).

- It facilitates behavior change in HIV positive people.

- It counsels HIV-negative clients to remain negative lifelong and HIV positive clients to prevent the further spread of HIV (positive prevention) as well as access the continuum of care services.

- Integrated Counseling and Testing Center helps patients to know their seropositive status, so that they can cope up with the reality.

- They also get psychosocial support through various referral systems including district-level networks.

- It identifies the need for people living with HIV requirement and prevents opportunistic infections prophylaxis. It also provides access to antiretroviral treatment centers. 
Brief Review of Integrated Counseling and Testing Center

Table 1: Distribution of patients based on year of attending ICTC, gender, and HIV status

\begin{tabular}{lllll}
\hline Year & Total referred & Male HIV positive (\%) & Female HIV positive (\%) & Total HIV positive (\%) \\
\hline 2014 & 13,433 & $70(0.6 \%)$ & $53+$ ANC-01 $(0.5 \%)$ & $124(1.1 \%)$ \\
2015 & 20,152 & $53(0.3 \%)$ & $31+$ ANC-02 $(0.2 \%)$ & $86(0.5 \%)$ \\
2016 & 12,567 & $37(0.29 \%)$ & $16+$ ANC-02 $(0.14 \%)$ & $55(0.43 \%)$ \\
\hline Total & 46,152 & $160(0.34 \%)$ & $100+$ ANC-05 $(0.22 \%)$ & $265(0.57 \%)$ \\
\hline
\end{tabular}

Chi-square $=14.86, p<0.001 ;$ ANC: Antenatal clinic

- Parent-to-child transmission of HIV can be prevented by counseling the clients and giving them moral support.

- It screens for tuberculosis (TB) symptoms and refers patients for diagnosis and treatment.

- It facilitates early treatment of HIV-related infections and sexually transmitted infections (STIs).

- It encourages orphan care.

- It is not the duty of the ICTC to counsel and test everyone in the general population.

General principles of HIV testing should be part of the overall comprehensive and preventive program.

- Testing should be technically sound and appropriate.

- Test procedure must be cost-effective.

- Laboratory procedure must be monitored for ensuring quality.

- A number of moral, legal, ethical, and psychological issues are related to a positive HIV status; hence, any laboratory attempting to assess the HIV status of an individual should be conversant with these issues.

\section{Location of ICTC}

- Maternity homes/hospitals with $>50$ deliveries in a month

- Hospitals/clinics-TB Microscopy Center

- Hospitals/clinics that have a case load of $>100$ STIs in a month

- Diagnostic laboratories that perform $>150$ diagnostic HIV tests in a month

- Industrial zones that employ a large number of people, particularly migrants/casual labor on an informal/ contractual basis.

\section{OBJECTIVE}

To estimate the client profile of ICTC in RajaRajeswari Medical College \& Hospital (RRMCH), Bengaluru, Karnataka, India during the years 2014 to 2017.

\section{MATERIALS AND METHODS}

The study was conducted by reviewing case records and interrogation of patients attending ICTC in RRMCH, Bengaluru, Karnataka, India.

Statistical analysis: Data are expressed as frequency and percentage. Statistical tests applied included univariate analysis and Chi-square test.

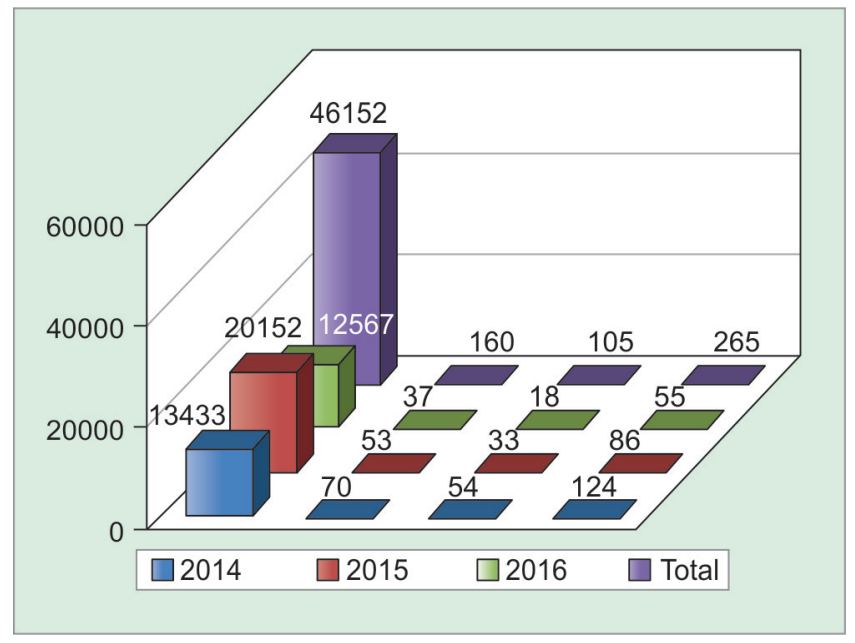

Graph 1: Number of patients according to year of attending ICTC in RRMCH

\section{RESULTS}

A total of 46,152 persons were tested during 2014 to 2016. Of the total tested, $265(0.57 \%)$ were HIV positive of whom $160(60.37 \%)$ were males and $105(39.63 \%)$ were females; $0.5 \%$ of the HIV positive women were antenatal mothers (Table 1 and Graph 1). Occupations of HIV positive patients: $50 \%$ were agriculturists, $25 \%$ truck/taxi/ auto drivers, $10 \%$ garment workers/factory workers, $10 \%$ construction workers/migrants, and others $5 \%$ (Table 2 and Graph 2). In the present study, sexual mode of transmission and lower socioeconomic status predominates among $95 \%$ of HIV positives.

There has been an overall reduction in the HIV positive persons being detected every year from 2014 to 2017 and the difference is statistically significant.

Table 2: Distribution of patients based on month of attending ICTC (Jan-June 2017), gender, and HIV status

\begin{tabular}{lllll}
\hline Month & $\begin{array}{l}\text { Total } \\
\text { referred }\end{array}$ & $\begin{array}{l}\text { Male HIV } \\
\text { positive }\end{array}$ & $\begin{array}{l}\text { Female HIV } \\
\text { positive }\end{array}$ & $\begin{array}{l}\text { Total HIV } \\
\text { positive }\end{array}$ \\
\hline Jan & 970 & 2 & 1 & 3 \\
Feb & 1,035 & 2 & 5 & 7 \\
Mar & 1,116 & 3 & - & 3 \\
Apr & 855 & 3 & 6 & 9 \\
May & 1,280 & 7 & 7 & 14 \\
June & 1,246 & 3 & 4 & 7 \\
\hline Total & 6,502 & $20(0.3 \%)$ & $23(0.35 \%)$ & $43(0.66 \%)$ \\
\hline
\end{tabular}




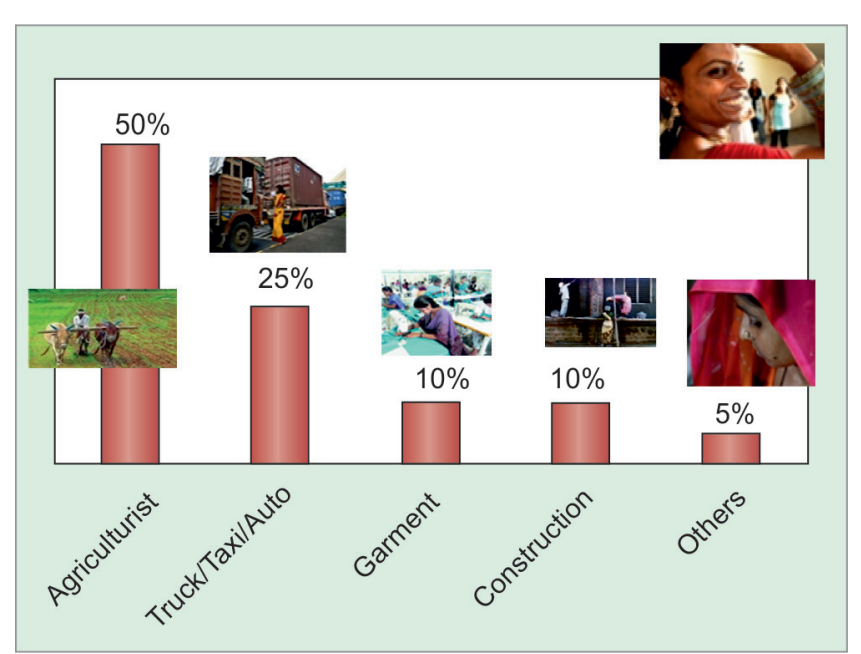

Graph 2: Occupation distribution of persons detected as HIV positive

\section{DISCUSSION}

The prevalence of HIV among ICTC clients in the present study was noted to be $0.57 \%$, which is lower than that reported from a study conducted in Udupi, Southern Karnataka (9.6\%) in $2007^{7}$ and also from a study in Ahmedabad (4.8\%). ${ }^{8}$

In the present study, the percentage of male attendees to ICTC for testing is higher $(58.79 \%)$ compared with females $(41.2 \%)$. This is similar to the study in Udupi, Southern Karnataka with $64.7 \%$ males and 35.3\% females. ${ }^{7}$

The vast majority of HIV infections in India occur through sexual transmission $(85.6 \%) .{ }^{3}$ In this present study, sexual mode of transmission was predominant $(88 \%)$.

Implementation of ICTC under public-private partnership, under the guidance of National AIDS Control Organization, India, at all the private hospitals, especially in the Department of Dermatology (in coordination with other departments) having high-risk patients (with sexually transmitted diseases) contributes a lot toward HIV/AIDS control and further delinks the dynamics of HIV/AIDS transmission. ${ }^{9,10}$

\section{CONCLUSION}

The current study shows that $0.57 \%$ persons attending ICTC in RRMCH have HIV/AIDS. Each year (from 2014 to 2017) HIV positive persons detected are reduced. Among the total patients (mean of 15,384 per year) referred to ICTC, $0.67 \%$ are positive.

Also, almost $95 \%$ of HIV positives belong to lower socioeconomic status, and among HIV positives, agriculturists predominate being about $50 \%$. Main mode of spread of disease is sexual mode. Hence, information, education, and communication on HIV/AIDS and its prevention need to be intensified on a regular basis, including safe sex promotion and implementing HIV/ AIDS and TB policy at the workplace.

\section{RECOMMENDATIONS}

Information, education, and communication on HIV/ AIDS and its prevention need to be intensified among rural people who are having minimal awareness, hardly practice safe sex (issues like condom usage and its disposal), and have stigma attached to sexually transmitted diseases. In villages, community participation could be utilized for spreading awareness and involving the rural people to take part in health education activities on prevention of HIV/AIDS.

\section{REFERENCES}

1. World Health Organization Update-HIV global scenario; 2017. Available from http://www.who.int/gho/hiv/en/ [accessed 25 Dec 2017].

2. World Health Organization-United Nations-HIV in India; 2017. Available from http://www.unaids.org/en/regionscountries/countries/india [accessed 25 Dec 2017].

3. Government of India. NACP III. To halt and reverse the HIV epidemic in India. New Delhi: NACO, Ministry of Health and Family Welfare; 2007.

4. World Health Organization. Global Health Observatory Data Repository. India statistics summary. Geneva. Available from http://apps.who.int/gho/data/?theme= country\&vid=10400 [accessed 22 Aug 2017].

5. UNICEF. India-HIV/AIDS. Available from www.unicef. org/india/hiv_aids.html [accessed 20 Aug 2017].

6. Government of India. HIV Sentinel Surveillance 2012-13. A Technical Brief. Department of AIDS Control. National AIDS Control Organization. Ministry of Health \& Family Welfare. Available from www.naco.gov.in [accessed 25 Aug 2017].

7. Kumar A, Kumar P, Gupta M, Kamath A, Maheshwari A, Singh S. Profile of clients tested HIV positive in a voluntary counseling and testing center of a District Hospital, Udupi, South Kannada. Indian J Community Med 2008 Jul;33(3):156-159.

8. Sharma R. Profile of attendee for voluntary counselling and testing in the ICTC, Ahmedabad. Indian J Sex Transm Dis AIDS 2009 Jan-Jun;30(1):31-36.

9. Government of India. HIV declining in India; New infections reduced by 50\% from 2000-2009; Sustained focus on prevention required. Department of AIDS Control. National AIDS Control Organization. New Delhi: Ministry of Health \& Family Welfare; December 2010. Available from http://www. naco.gov.in/upload/Publication/M\&E\%20Surveillance, $\% 20$ Research/NACO\%20Press\%20Release\%20on\%20HIV\%20 Estimates.pdf [accessed 10 Aug 2017].

10. Government of India. Operational Guidelines for Integrated Counselling \& Testing Centers. National AIDS Control Organization. New Delhi; Ministry of Health and Family Welfare; December 2016. 